\title{
Oportunidades de las minicadenas productivas del sector cacao de Santander frente al pos conflicto colombiano ${ }^{1}$
}

\section{Opportunities of the productive minicadenas of the cacao sector of Santander against the colombian post-conflict}

\author{
DOI: https://doi.org/10.17981/econcuc.40.2.2019.10
}

Artículo de investigación. Fecha de recepción: 29/03/2019 Fecha de aceptación: 20/08/2019

\author{
Julio Ramírez Montañez \\ Universidad Pontificia Bolivariana. (Bucaramanga, Colombia) \\ julioramire@yahoo.com \\ Gladys Mireya Valero Córdoba \\ Universidad Pontificia Bolivariana. (Bucaramanga, Colombia) \\ gladys.valero@upb.edu.co \\ Paola Martínez Higuera \\ Universidad Pontificia Bolivariana. (Bucaramanga, Colombia) \\ paola.martinez@upb.edu.co
}

Para citar este artículo:

Ramírez, J., Valero, G. y Martínez, P. (2019). Oportunidades de las minicadenas productivas del sector cacao de Santander frente al pos conflicto colombiano. Económicas CUC, 40(2), 153-182. DOI: http://dx.doi.org/10.17981/econcuc.40.2.2019.10

\section{Resumen}

El sector cacao resulta ser uno de los sectores más tradicionales en el departamento de Santander, ello se debe a la gran cantidad de familias que se benefician económicamente de su cultivo, aunado a ello luego de la firma del acuerdo de paz el cacao se ha convertido en una de las apuestas productivas agroindustriales de Colombia, utilizándolo, como estrategia de sustitución de cultivos ilícitos en el contexto del posconflicto. Este artículo tuvo como objetivo analizar las oportunidades de las minicadenas productivas del sector cacao del departamento de Santander con el fin de determinar posibles opciones de inserción de los productos del cacao a cadenas globales de valor en el periodo pos conflicto. Para ello se implementó una metodología de tipo descriptiva para determinar las características de la cadena productiva del sector cacao de Santander mediante la aplicación del modelo minicadenas productivas proporcionada por la Agencia da las Naciones Unidas de Desarrollo Industrial (ONUDI). En virtud del análisis realizado, se pudo determinar que la cadena agroindustrial del cacao en Colombia es un sector estratégico en la región que cuenta con unidades productivas integrando labores de cultivo, cosecha, post cosecha, acopio, comercialización y empresas productoras de bienes finales, además ha presentado exportaciones en los últimos años. Se concluye que las políticas públicas de Colombia han priorizado al cacao como materia prima de interés para el desarrollo rural, desplegando acciones gubernamentales y de cooperación internacional encaminadas a consolidar una adecuada cadena de valor y de esa forma solventar las necesidades tecnológicas y organizativas de un sector agrícola clave en el proceso de sustitución de cultivos ilícitos en el pos conflicto.

Palabras clave: Agroindustria; cacao, valor, comercio, producción

\section{Abstract}

The cocoa sector turns out to be one of the most traditional sectors in the department of Santander, this is due to the large number of families that benefit economically from its cultivation, added to this after the signing of the peace agreement, cocoa has become in one of Colombia's productive agroindustrial bets, using it as a strategy to substitute illicit crops in the post-conflict context. The objective of this article was to analyze the opportunities of the mini-production chains in the cocoa sector in the department of Santander in order to determine possible options for the insertion of cocoa products into global value chains in the post-conflict period. To do this, a descriptive methodology was implemented to determine the characteristics of the production chain in the Santander cocoa sector through the application of the mini-production chain model provided by the United Nations Agency for Industrial Development (UNIDO). By virtue of the analysis carried out, it was possible to determine that the agro-industrial chain of cocoa in Colombia is a strategic sector in the region that has production units integrating cultivation, harvesting, postharvest, storage, marketing and production companies of final goods, it has also presented exports in recent years. It is concluded that the public policies of Colombia have prioritized cocoa as a raw material of interest for rural development, deploying governmental actions and international cooperation aimed at consolidating an adequate value chain and thus solving the technological and organizational needs of a key agricultural sector in the post-conflict process of replacing illicit crops.

Keywords: Cocoa sector; the department of Santander; value chains; post-conflict

${ }^{1}$ Articulo resultado del proyecto de investigación titulado "Inserción de Productos del sector Cacao de Santander a Cadenas Globales de Valor" desarrollado por el Semillero en Gerencia Internacional (SIGI) de la facultad de Administración de Negocios Internacionales de la Universidad Pontificia Bolivariana, Seccional Bucaramanga (Colombia) conjuntamente con el semillero Clúster de la Facultad de Negocios Internacionales de la Universidad Santo Tomas de Bucaramanga (Colombia) con la financiación de Gen conciencia del Programa Ondas. 


\section{INTRODUCCIÓN}

De acuerdo al Ministerio de Agricultura y Desarrollo Rural-MADR (República de Colombia, 2016) el cacao es una de las apuestas productivas agroindustriales de Colombia para el periodo posterior a la firma de los acuerdos de paz de la Habana, por su importancia en el desarrollo y apoyo a la sostenibilidad social, tanto así que muchos lo denominan "El cultivo de la paz". Este cultivo es considerado estratégico, por el gobierno nacional y la comunidad internacional por ser canalizador del aprovechamiento del campo, como una de las estrategias en el contexto del posconflicto, específicamente en lo relacionado con la sustitución de cultivos ilícitos y la generación de proyectos productivos, tanto para los desmovilizados, como para la población víctima del conflicto armado.

Es tal la importancia de este sector, que en el Plan Nacional de Desarrollo de Colombia (PNUD, 2014-2018) quedó establecido que el cultivo del cacao seria uno de los sectores agroindustriales priorizados en el plan "Colombia Siembra" como política agropecuaria del gobierno nacional (MADR, 2016). Así mismo, el Ministerio de Industria, Comercio y Turismo, a través del Programa de Transformación Productiva (PTP), priorizó desde el año 2013 el sector agroindustrial del cacao con el desarrollo de acciones encaminadas a incrementar la productividad, eficiencia, calidad, y la investigación y desarrollo en el sector productivo.

El gobierno nacional y la comunidad internacional vienen apostándole a este cultivo, a través de diversas iniciativas como el programa Colombia Siembra, liderado por el Ministerio de Agricultura, el proyecto "Cacao para la Paz" de la Agencia de Cooperación de Estados Unidos-USAID y el "Proyecto de Promoción de la Producción y Exportación de Cacao Fino y de Aroma en Colombia", del Programa Suizo de Cooperación al Desarrollo Económico en Colombia (SECO).

Es importante señalar que el sector cacaotero es uno de los de mayor tradición el departamento de Santander debido a la gran cantidad de familias que dependen de esta actividad económica, con unas condiciones agrícolas propicias y las características distintivas en materia de variedad del grano han permitido a Santander ubicarse en el primer lugar en la lista de productores de cacao del país con una producción de 19.957 toneladas en el año 2016. Dichas ventajas comparativas se deben en especial a la disponibilidad de una gran área cultivable, así como a las condiciones climáticas adecuadas. Estos factores naturales, junto a aspectos culturales y sociales, han favorecido un importante arraigo alrededor del cultivo, aspecto que permite vislumbrar para esta actividad económica posibilidades reales de fomentar un crecimiento y un desarrollo económico sostenible y perdurable (Botero, 2016).

Las indagaciones previas frente a la temática en cuestión señalan que los productores de cacao del departamento de Santander tienen muchas oportunidades en el periodo del pos conflicto colombiano de ingresar a cadenas globales de valor al haber sido priorizado por el gobierno nacional como uno de los productos agropecuarios con mayor potencial, gracias al reconocimiento mundial de la calidad de los genotipos que se cultivan en Santander, con lo cual pudiera posicionarse en el 
nicho de cacaos especiales. Sin embargo, los investigadores del presente artículo destacan los constantes problemas en los eslabones componentes de la cadena agroindustrial del sector cacao de Santander los cuales han sido identificados previamente por investigadores y entidades públicas, donde se subrayan aspectos como el bajo desarrollo tecnológico en las operaciones de transformación en las principales zonas productoras, el desconocimiento de los parámetros de calidad por parte de los eslabones de productores y comercializadores, el desconocimiento de los requisitos de los mercados internacionales y los problemas de asociatividad, confianza e integración de los eslabones de la cadena (Contreras, 2017).

De igual forma, diferentes instancias del sector público y privado recomiendan darle continuidad al proceso de trabajo conjunto entre los actores de la cadena agroindustrial del sector cacao con el proyecto del "Clúster del Cacao". Este reto está impulsado por la Cámara de Comercio de Bucaramanga y las empresas del sector en pos del mejoramiento de la calidad y el posicionamiento del producto en mercados internacionales y debe ser apoyado por todos los componentes de esta cadena.

\section{Desarrollo}

La cadena productiva es un concepto que proviene de la escuela de la planeación estratégica. Según esta escuela, la competitividad de una empresa se explica no solo a partir de sus características internas a nivel organizacional o micro, sino que también está determinada por factores externos asociados a su entorno (Bonilla, Cardeño y Cardeño, 2015).
En las dos últimas décadas los encadenamientos productivos, la competitividad, la productividad basada en la innovación y la internacionalización de las empresas, han venido siendo los cuatro ejes principales de la política industrial moderna de un país para que las empresas crezcan, compitan, generen empleo y conquisten nuevos mercados (Espejel, Illescas, Hernández, Santos y Ramírez, 2018; Ramírez y González, 2016).

Estas tendencias vienen marcando la vanguardia en la gerencia internacional donde se tiene la necesidad de insertarse en las cadenas globales de valor antes de continuar con un modelo de intercambio basado en países y bloques. Los gerentes de las empresas en el siglo XXI deben pensar en cómo lograr encadenamientos productivos que permitan que sus productos se integren en procesos internacionales sacando ventaja de los acuerdos de libre comercio (Pérez, Hernández, Acosta y Chumaceiro, 2009). Siendo estos encadenamientos la llave para ingresar con fuerza a las cadenas globales de valor, lo que se traduce en una mayor fortaleza y competividad para las industrias de los países emergentes (Ramírez y González, 2016).

El eje temático de esta investigación es el estudio de las cadenas productivas. Los primeros acercamientos al concepto de cadena productiva parten de las teorías de eslabonamientos propuestas por Albert Hirschman en 1958. Este autor define la cadena productiva como el conjunto de fuerzas que generan inversiones y que son accionadas cuando la capacidad productiva de los sectores que producen insumos para esa línea y que utilizan los productos de esta es insuficiente (Castellanos, Rojas, Villaraga y Ustate, 2001). 
El fortalecimiento conceptual sobre la temática provino con Michael Porter en la década de los años noventa (Porter, 1990). De acuerdo con este autor, la cadena de valor describe las actividades que lleva a cabo una empresa al competir en un sector agrupándolas en dos categorías: En la primera categoría están aquellas relacionadas con la producción, comercialización, entrega y servicio postventa de los productos y servicios que oferta la empresa y en la segunda categoría las actividades que proporcionan elementos de soporte como recursos humanos, tecnología, insumos e infraestructura (Porter, 1990).

Adicionalmente, Porter (1990) determina la cadena de valor como el sistema interdependiente o red de actividades, conectado mediante enlaces. Los enlaces se producen cuando la forma de llevar a cabo una actividad afecta el coste o la eficacia de otras actividades. Frecuentemente, los enlaces crean situaciones en las que si se opta por algo tiene que ser a cambio de renunciar a otra cosa, sobre todo en lo que se refiere a la realización de diferentes actividades que deban optimizarse.

De igual forma, Porter (1990) señala que dentro de los principales elemen- tos básicos que constituyen una cadena de valor se encuentran actividades primarias que van desde el desarrollo del producto, labores de producción y fabricación, funciones logísticas y de comercialización hasta servicios de posventa y actividades de soporte a las primarias como la administración de recursos humanos, compras, desarrollo tecnológico, aspectos de la estructura empresarial, aspectos organizaciones, financieros y legales. Otro elemento que presenta Porter en la teoría de la ventaja competitiva está relacionado con tipos de cadenas de valor: Cadena de valor de los proveedores, cadenas de valor de los canales y cadenas de valor de los compradores.

De otra parte, la Organización de las Naciones Unidas para el Desarrollo Industrial (ONUDI) define la cadena productiva como un conjunto estructurado de procesos de producción que tiene en común un mismo mercado y en el que las características tecno productivas de cada eslabón afectan la eficiencia y productividad de la producción en su conjunto" (ONUDI, 2004)

La Organización de las Naciones Unidas para el Desarrollo Industrial (ONUDI) diagrama la cadena de valor de la siguiente forma (Figura 1):

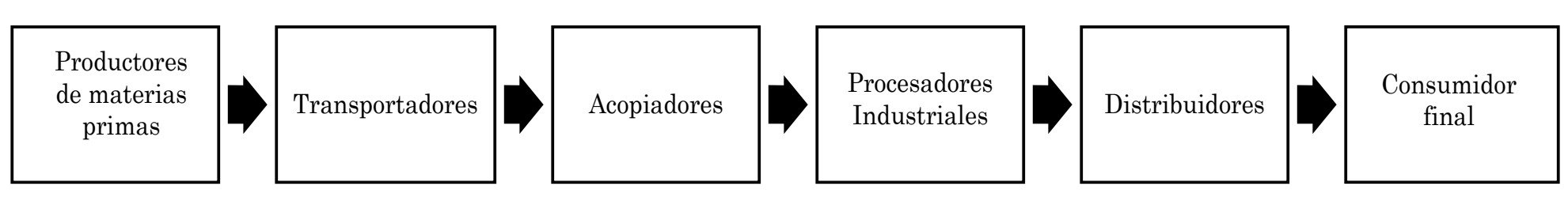

Figura 1. Esquema Cadena de Valor.

Fuente: Elaboración propia de datos de ONUDI, 2004. 
Como se puede apreciar en la Figura 1, las cadenas productivas se subdividen en eslabones, los cuales comprenden conjuntos de empresas con funciones específicas dentro del proceso productivo. A manera de ejemplo, el primer eslabón dentro de la cadena productiva del cacao lo constituyen los cultivadores del grano; en el segundo, los transportadores; el tercero, los centros de acopio; el cuarto, los procesadores del grano; el quinto, los productores; el sexto, los distribuidores y comercializadores, y el séptimo y último, los consumidores de chocolates

En cuanto a la temática especifica de cadena de valor agroalimentaria, Contreras (2017) la define como la cadena de actividades desde la producción en el establecimiento agropecuario, seguida de la etapa de procesamiento hasta la distribución mayorista y minorista. Por su parte, Holmlund \& Fulton (1999) definen la cadena de valor agroalimentaria como una red de alianzas verticales o estratégicas entre varias empresas de negocios independientes dentro de una cadena agroalimentaria.

En ese mismo sentido la Agencia de las Naciones Unidas para la Alimentación y la Agricultura (FAO, 2015) extiende el concepto a cadena de valor alimentaria sostenible como todas aquellas explotaciones agrícolas y empresas, así como las posteriores actividades que de forma coordinada añaden valor, que producen determinadas materias primas agrícolas y las transforman en productos alimentarios concretos que se venden a los consumidores finales y se desechan después de su uso, de forma que resulte rentable en todo momento, proporcione amplios beneficios para la sociedad y no consuma permanentemente los recursos naturales (FAO, 2015)

En esa línea, Pietrobelli y Staritz (2013) sostienen que el enfoque de cadenas de valor debe hacer hincapié en la importancia de la aparición de los actores de empresariales, como estados y organizaciones internacionales, ONG'S, organismos de investigación e instituciones reguladoras. Con el creciente paso e interacción de esos actores desligados de la centralización, el concepto de las cadenas globales de valor parece haber luchado frente al desprestigio de ciertos organismos que sirvieron como soporte en su comienzo. Por lo que ahora se muestra como una nueva herramienta interpretación-acción dentro de la agenda económica internacional (Fernández y Trevignani, 2015).

Para que una unidad productiva o empresa actúe bajo el enfoque de cadena de valor, debe considerarse parte activa de una red de empresas y actores que buscan optimizar un bien o servicio, como una estructura que mantiene dinámica permanente por medio de relaciones empresariales, a fin de dar respuesta de manera colectiva y solidaria a una demanda final en un espacio económico de relaciones productivas de bienes y servicios. Estos eslabones de la cadena de valor pueden ser desarrollados por una sola firma de una manera integrada; o puede darse por varias firmas independientes que aportan a la cadena un conjunto de actividades y recursos enfocados al bien y es el caso de una industria desverticalizada (Cardona y López, 2009).

\section{Metodología}

Para el desarrollo de la investigación se aplicó un análisis de tipo descriptivo sobre las características de los vínculos en la cadena productiva del sector cacao de Santander. De igual forma, tuvo un componente exploratorio mediante la implementación metodología "Minicadenas Productivas" proporcionada por la Agencia de las Naciones Unidas para el Desarrollo Industrial (ONUDI). Este análisis se desarrolló empleando esta meto- 
dología de análisis de cadenas productivas agroindustriales, mediante el uso articulado de herramientas de gestión como la vigilancia tecnológica y el diagnóstico por eslabones de cadenas productivas.

Para analizar la cadena de valor del sector cacao del departamento de Santander se ha tomado como referencia la metodología diseñada por la ONUDI denominada minicadenas productivas. Esta metodología está plasmada en un manual para orientar a los diferentes organismos e instituciones de apoyo en los procesos de identificación, conformación y desarrollo de minicadenas productivas. Este análisis se desarrolló mediante el uso articulado de herramientas de gestión como la vigilancia tecnológica y análisis por eslabones de cadenas productivas.

Esta investigación se desarrolló en las siguientes fases:

\section{Fase 1}

Esta primera fase se aplicó un análisis documental a través de fuentes secundarias de información en los últimos cinco años, tomando como referencia las variables de empleo, valor agregado, producción bruta, distribución, regional de la producción y principales productos exportados y destinos de las exportaciones de la cadena priorizada del sector Cacao de Santander

\section{Fase 2}

Implementación Metodología minicadenas productivas" (ONUDI) utilizando como instrumento guía el manual de orientación de la ONUDI en los municipios del departamento de Santander para el acceso a las unidades de la cadena de valor, mediante el uso articulado de herramientas de gestión como la vigilancia tecnológica y diagnóstico por eslabones de cadenas productivas.

\section{Fase 3}

Análisis de la información y construcción de la matriz de la minicadena productiva del cacao de Santander.

\section{Resultados}

López y Pineda (2013) explican como Colombia posee excelentes condiciones geoestratégicas que le permiten ser una plataforma logística natural para el comercio mundial; buenas condiciones climáticas, amplios recursos naturales y materias primas que permitirían el crecimiento industrial y de servicios para aquellas compañías y gobiernos que deseen invertir.

En ese sentido, la cadena agroindustrial del sector cacao es un sector estratégico en la región que cuenta con unidades productivas que integran labores de cultivo, cosecha, post cosecha, acopio, comercialización y empresas productoras de bienes finales y además ha presentado exportaciones en los últimos años. Esta etapa de integración se caracteriza por la creciente interconexión entre países, el aumento de la participación de los insumos intermedios en las importaciones mundiales y la especialización, tanto de los países como de las empresas, en determinadas tareas y funciones (Dalle, Fossati y Lavopa, 2013).

Asimismo, el subsector de la chocolatería y de la confitería hace parte del Programa de Transformación Productiva (PTP) del Ministerio de Comercio, Industria y Turismo de Colombia, que busca mejorar la competitividad sectorial mediante alianzas público-privadas y planes de negocios. Este hecho favorece al sector del cacao en Santander con la creación de relaciones directas con los comercializadores internacionales porque tienen el respaldo para las negociaciones. 
El reconocimiento oficial de la organización de la cadena Cacao-Chocolate se realizó ante el Ministerio de Agricultura y Desarrollo Rural, dando cumplimiento a la Ley 811 (2003) y sus decretos reglamentarios, en tal forma, el 17 de Noviembre de 2009, el Ministerio de Agricultura y Desarrollo Rural mediante la Resolución 000329 (2009), "reconoce la Organización de la Cadena de Cacao y su Agroindustria", así como al Consejo Nacional Cacaotero y a sus integrantes: productores (Fondo Nacional del Cacao- Fedecacao- y Asociaciones de Productores), sectores académicos y de Investigación, Gobierno Nacional, comercializadores e industriales como el "cuerpo consultivo del Gobierno Nacional en materia de política para el subsector del cacao" (Resolución 000329, 2009, Art. 2) (ver Tabla 1).

Esta cadena suscribió el Acuerdo Nacional de Competitividad en octubre de 2001, actualizado en el año 2013 y en el cual se establece como visión de la cadena: "Incrementar la producción nacional hasta alcanzar como mínimo 200.000 toneladas de grano en el año 2022, brindando sostenibilidad económica, social y ambiental a todos los eslabones de la cadena, conservando las características de grano fino para satisfacer las exigencias de los mercados Nacionales e internacionales, y posicionando a Colombia dentro de los principales países exportadores de productos elaborados y de cacaos especiales" (Contreras, 2017). Estas cifras de proyección están sustentadas en una producción de cacao para el año 2017 de 60.535 toneladas en el departamento de Santander, según datos oficiales de la Federación Nacional de Cacaoteros (Fedecacao).

ONUDI (2004) define a la minicadena como el agrupamiento de micro y pequeñas unidades productivas que se pueden articular alrededor de actividades económicas conexas y sostenibles, las cuales comprenden la producción de materias primas e insumos, la transformación y la comercialización, y usualmente hacen parte de una vocación económica regional. A través del agrupamiento las unidades productivas buscan aumentar sus posibilidades de desarrollo sostenible (ONUDI, 2004).

El estudio sigue un esquema de análisis por eslabones a lo largo de la minicadena y las variables de análisis se presentan en la Tabla 2.

TABLA 1

Consejo Nacional Cacaotero

\begin{tabular}{|c|c|c|}
\hline $\begin{array}{c}\text { Representantes } \\
\text { Industria }\end{array}$ & $\begin{array}{c}\text { Representantes } \\
\text { Gremios }\end{array}$ & Instituciones Publicas \\
\hline $\begin{array}{l}\text { Casa Luker } \\
\text { Compañía Nacional de } \\
\text { Chocolates } \\
\text { Chocolate Girones }\end{array}$ & $\begin{array}{l}\text { Fedecacao } \\
\text { ANDI }\end{array}$ & $\begin{array}{l}\text { Ministerio de Agricultura. } \\
\text { Ministerio de Comercio Industria y } \\
\text { Turismo. } \\
\text { Programa de Transformación Productiva. } \\
\text { Corpoica } \\
\text { Instituto Colombiano Agropecuario - ICA }\end{array}$ \\
\hline
\end{tabular}

Fuente: Elaboración Propia. 
TABLA 2

Modelo Minicadenas Productivas (ONUDI)

\begin{tabular}{ll}
\hline \multicolumn{1}{c}{ Eslabón } & \multicolumn{1}{c}{ Análisis } \\
\hline $\begin{array}{l}\text { Eslabón de materias } \\
\text { primas e insumos: }\end{array}$ & $\begin{array}{l}\text { Comprende las empresas dedicadas a la producción } \\
\text { de materiales básicos para la obtención del } \\
\text { Producto final. }\end{array}$ \\
Eslabón de & $\begin{array}{l}\text { Abarca las empresas que transforman las materias primas e insumos para la } \\
\text { obtención del producto o }\end{array}$ \\
producción & Servicio final y subproductos derivados. \\
Eslabón de & Incluye las empresas encargadas de la distribución y entrega del producto o \\
comercialización & servicio a los consumidores finales. \\
& Comprende las instituciones y entidades que proporcionan apoyo al proceso \\
& de consolidación de las minicadenas. Se incluyen en este componente \\
& el Gobierno nacional, los gobiernos regionales \\
Componente socio & y locales, las instituciones de capacitación y \\
empresarial & tecnológicos y de innovación), y entidades gubernamentales de apoyo \\
& $\begin{array}{l}\text { específico a la pequeña } \\
\text { y mediana empresa }\end{array}$ \\
& $\begin{array}{l}\text { Comprende los servicios necesarios para el funcionamiento de los eslabones } \\
\text { de la minicadena } \\
\text { tales como servicios públicos, infraestructura } \\
\text { de transporte, entidades financieras, servicios } \\
\text { de salud y entidades reguladoras de la actividad } \\
\text { empresarial }\end{array}$ \\
\hline
\end{tabular}

Fuente: Elaboración propia a partir de ONUDI, 2004.

A continuación, se procede a presentar los resultados de la aplicación de este modelo en la cadena agroindustrial del cacao en Santander.

\section{Aplicación Modelo Minicadenas Productivas ONUDI al Sector Cacao de Santander}

La cadena de cacao de Santander posee una gran cantidad de procesos y actores que inciden en la calidad del producto, pues el cacao en grano es la materia prima para las industrias de confitería y de producción de chocolates, cosméticos y farmacéuticos. La cadena productiva del cacao comprende tres tipos de bienes: El bien primario tomando como referencia al grano de cacao: Los bienes intermedios como aceite, manteca, polvo y pasta de cacao y los bienes finales como chocolate y sus preparados (Superintendencia de Industria y Comercio, 2016).

En esta sección se presentan los resultados de la aplicación de la metodología diseñada por la Organización de las Naciones Unidas para el Desarrollo Industrial (ONUDI) denominada minicadenas productivas, tomando como referencia a cada uno de los eslabones de la cadena del sector cacao en el departamento de Santander 


\section{Análisis del Eslabón de Materias \\ Primas e Insumos de la Cadena del Cacao de Santander:}

Para realizar el análisis del eslabón de materias primas del sector cacao de Santander se han tomado como variables de análisis los proveedores de insumos en la cadena agroindustrial del cacao del departamento, las características en el cultivo del grano en el departamento de Santander y la producción agrícola de la cadena.

\section{- Proveedores de Insumos en la Cadena del Cacao en Santander:}

Los proveedores de insumos integran las actividades de quienes comercializan insumos y materias primas necesarias para el cultivo del cacao y para los procesos de transformación propios de la agroindustria. Los proveedores de insumos en la cadena se clasifican en dos grandes grupos: los proveedores de insumos para el cultivo, donde se encuentran aquellos comercializadores de material vegetal, agroquímicos y pesticidas, y los proveedores de herramientas y equipo para el cultivo del cacao en las fincas; por otro lado, se encuentran aquellos proveedores de insumos y materias primas para la agroindustria dedicada a la transformación (Departamento Nacional de Planeación-DNP, 2014)

De acuerdo a Oliveros (2013) la gran mayoría de los productores de cacao de Santander compran sus insumos en los pueblos más cercanos a sus cultivos, lo cual les da a los proveedores un amplio control sobre la obtención de las materias primas. Los principales productos demandados por los productores de cacao son fertilizantes como la urea, triple 15 tradicional y cafetero, DAP, entre otros, con precios que oscilan desde los $\$ 54.000 /$ bulto hasta los $\$ 95.000 /$ bulto. El siguiente grupo de productos demandados son los cicatrizantes de podas, tales como cal dolomita, pasta cicatrizante, oxicloruro de cobre, entre otros, con precios que varían desde los $\$ 7.500 / \mathrm{kg}$ hasta los $\$ 23.000 / \mathrm{kg}$ y en tercer grupo se encuentran los herbicidas, fungicidas e insecticidas, donde se resalta el uso de glifosato (Contreras, 2017)

\section{- Características de los Cultivos del Cacao en Santander:}

El cacao es un sistema completo de cultivo que requiere la utilización de mano de obra intensiva y configura una explotación típica de economía campesina, con un desarrollo lento en el caso del departamento de Santander, debido a factores de orden social y económico. Santander se constituye en un departamento productor, con unas potencialidades de desarrollar mayor valor a la cadena global del cacao que puede ser desarrollado por empresas que transformen el producto con altos estándares de calidad y mayor tecnología de punta. (Oliveros, 2013)

Oliveros (2013) destaca que el cultivo del cacao en el departamento de Santander, es una labor que se ha venido realizando de generación en generación. Desde el punto de vista social y económico la producción de cacao tiene especial importancia en Santander, teniendo en cuenta que cuenta con las condiciones aptas de suelos y clima para llevar a cabo este cultivo, adicional a esto es importante mencionar que es un cultivo de bajo costo lo que es conveniente para los campesinos dedicados a producir cacao ya que en su mayoría son de escasos recursos.

De acuerdo a Lozano, Vega y Varilla (2017) los agricultores dedicados a la producción de cacao en Santander en su gran 
mayoría son arrendatarios, dueños o empleados, y la cosecha obtenida del cultivo es el único medio de subsistencia de su familia. La rivalidad de los cacaoteros es alta dada la gran cantidad de agricultores de la zona rural Santandereana, y dado que las condiciones de suelos y climáticas en este departamento son óptimas para que la producción de cacao pueda llevarse a cabo en casi todo el departamento. Adicional a esto las fincas dedicadas a este cultivo tienen una extensión promedio entre 1 y 20 hectáreas, por lo cual el cultivo se da incluso en fincas de pequeña extensión generando mayor rivalidad por la cantidad de productores dedicados a este cultivo.

En cuanto a la rivalidad entre los productores de cacao en Santander (Oliveros, 2013) es enfática al señalar que la competencia entre los agricultores del departamento es extremadamente alta debido a la gran cantidad de agricultores de la zona y a las barreras emocionales ancestrales entre ellos.

Otro factor de análisis fue el tamaño de cultivos de cacao en el departamento. En este punto se puede señalar que en San Vicente del Chucurí y el Carmen de Chucurí el tamaño promedio de los cultivos de cacao es de seis hectáreas, éstas se hallan concentradas en un $67,1 \%$ en tamaños comprendidos entre tres y diez hectáreas, principalmente se trata de cultivos de tipo familiar para el sustento de los integrantes del núcleo familiar, pero no están concebidos como unidades agrícolas familiares (Oliveros, 2013).

Finalmente, en cuanto al factor de valoración de la mano de obra en la cadena agroindustrial del cacao del departamento de Santander, según estudio reciente publicado por el Banco de la Republica (Mojica y Paredes, 2016) las labores agrícolas relacionadas al cacao son desempeñadas por mano de obra de baja calificación. Por otra parte, la explotación del cacao es de carácter familiar, hecho que propicia una amplia participación de los integrantes de este núcleo en la producción, siendo las actividades de recolección, apertura y desgrane las de mayor participación de mano de obra femenina. En muchos casos y durante buena parte del año, la unidad productiva necesita personal temporal adicional para las labores de manejo del cultivo tales como la poda, deshierbe, cosecha y desgrane Lo anterior se torna crítico al considerar que las actividades más delicadas del proceso (fertilización y control de plagas) requieren de personal calificado.

\section{- Producción Agrícola del Cacao en Santander 2014-2016}

Este cultivo se da a lo largo de todo el país, sin embargo, el $60.1 \%$ de la producción nacional se concentra en los departamentos de Santander, Norte de Santander, Arauca y Antioquia. El departamento de Santander, es el mayor productor del país, concentrando casi el 32\% de la producción nacional en el año 2016.

La Tabla 3 señala la producción de cacao en el año 2016 expresada en toneladas. El cacao ha venido mostrando unas cifras de crecimiento interesantes en el país, logrando una producción record de 62,000 toneladas para el año 2016. En la tabla 3 se observa como la producción nacional de cacao recae en mayor parte en los cultivos del departamento de Santander, especialmente en los municipios de San Vicente de Chucuri y Carmen del Chucuri con una producción de 19.957 toneladas en el año 2016. Lo siguen muy de lejos los departamentos de Arauca, Antioquia y Huila con tan solo el $7 \%$ de los cultivos en cada departamento. 
TABla 3.

Cifras de Producción Departamento 2014-2016.

\begin{tabular}{lrrrrrrl}
\hline \multirow{2}{*}{ Departamentos } & \multicolumn{5}{c}{ Área (Ha) } & \multicolumn{5}{c}{ Producción (Ton) } \\
\cline { 2 - 8 } & 2014 & 2015 & 2016 & 2014 & 2015 & 2016 & Part. 2016 \\
\hline Santander & 49.078 & 52.078 & 58.078 & 18.173 & 19.720 & 19.957 & $32 \%$ \\
N. Santander & 12.874 & 13.174 & 15.396 & 2.411 & 2.652 & 2.845 & $4 \%$ \\
Nariño & 12.648 & 12.948 & 14.448 & 3.586 & 3.715 & 3.894 & $6 \%$ \\
Huila & 12.314 & 12.614 & 13.614 & 4.164 & 4.280 & 4.324 & $6.9 \%$ \\
Antioquia & 11.670 & 12.170 & 12.870 & 3.777 & 3.900 & 4.005 & $6.45 \%$ \\
Arauca & 10.376 & 10.676 & 11.126 & 2.224 & 2.462 & 4.687 & $7 \%$ \\
Otros & 44.054 & 51.340 & 54.468 & 13.397 & 18.021 & 22.288 & $35 \%$ \\
Total & 153.014 & 165.000 & 180.000 & 51.023 & 54.750 & 62.000 & $100 \%$ \\
\hline
\end{tabular}

Fuente: Fedecacao, 2016.

De acuerdo a la información obtenida de Fedecacao se puede observar la producción nacional del producto en los departamentos de Colombia. En la primera posición se ubica Santander, el cual ha mantenido durante los siete últimos años la mayor producción de cacao a nivel nacional.

TABLA 4.

Producción de Cacao por municipio de Santander en el año 2017.

\begin{tabular}{ccc}
\hline Municipio & $\begin{array}{c}\text { Área } \\
\text { Cosechada(ha) }\end{array}$ & Producción(t) \\
\hline San Vicente de & 11,458 & 6,302 \\
Chucuri & 11,501 & 6,096 \\
El Carmen & 5,385 & 2,854 \\
de Chucuri & 4,735 & 2,699 \\
Landázuri & 1,673 & 1,004 \\
Rionegro & 788 & 402 \\
Cimitarra & 1,01 & 515 \\
Santa Helena & 1,164 & 559 \\
del Opón & 811 & 430 \\
Lebrija & 626 & 307 \\
El Playón & 482 & 256 \\
La Belleza & 179 & 108 \\
Sucre & 442 & 340 \\
Girón & 305 & 147 \\
La Paz & 407 & 232 \\
Betulia & & \\
Bolívar & & \\
El Peñón & &
\end{tabular}

\begin{tabular}{|c|c|c|}
\hline Municipio & $\begin{array}{c}\text { Área } \\
\text { Cosechada(ha) }\end{array}$ & Producción(t) \\
\hline Bucaramanga & 318 & 169 \\
\hline Guadalupe & 295 & 216 \\
\hline El Guacamayo & 325 & 185 \\
\hline Vélez & 282 & 138 \\
\hline Florián & 226 & 142 \\
\hline Guapota & 183 & 145 \\
\hline Chima & 183 & 143 \\
\hline Simacota & 165 & 112 \\
\hline Barrancabermeja & 166 & 85 \\
\hline Chipata & 184 & 90 \\
\hline Piedecuesta & 85 & 40 \\
\hline Socorro & 164 & 140 \\
\hline Puerto Parra & 72 & 36 \\
\hline Sabana de Torres & 116 & 64 \\
\hline Hato & 114 & 56 \\
\hline Palmas del Socorro & 96 & 56 \\
\hline Zapatoca & 96 & 46 \\
\hline Contratación & 74 & 46 \\
\hline Galán & 28 & 15 \\
\hline Oca monte & 29 & 18 \\
\hline Matanza & 33 & 20 \\
\hline Valle De San José & 27 & 11 \\
\hline Paramo & 27 & 15 \\
\hline Floridablanca & 37 & 27 \\
\hline Palmar & 19 & 8 \\
\hline Oiba & 15 & 12 \\
\hline San Benito & 15 & 11 \\
\hline Charta & 3 & 3 \\
\hline
\end{tabular}

Fuente: Datos Abiertos (2017). 
En la Tabla 4 se puede apreciar como el cultivo del cacao se registra en 42 municipios del departamento de Santander. Sin embargo, el 80\% de las áreas cosechadas y la producción de la cadena agroindustrial del sector cacao se limita a cinco municipios. El más importante de ellos es San Vicente De Chucuri con una producción de 6,302 toneladas en el año 2017, lo sigue muy de cerca El Carmen de Chucuri con 6,096 toneladas, y con menor producción Landázuri con 2,854, Rionegro con 2,699 y Cimitarra con 1,004 Toneladas registradas en el año 2017. El resto de municipios presentan cifras inferiores a las 500 toneladas en el año 2017.

La síntesis del Eslabón de materias primas e insumos se presenta en la Tabla 5:

TABLA 5.

Resultado Eslabón de materias primas e insumos de la cadena del cacao de Santander.

\begin{tabular}{|c|c|}
\hline Eslabón & Análisis \\
\hline \multirow{10}{*}{$\begin{array}{l}\text { Eslabón de } \\
\text { materias } \\
\text { primas e } \\
\text { insumos }\end{array}$} & $\begin{array}{l}\text { Actividades: Procesamiento, Torrefacción, Trillado, alcalinización, Molida, Prensado, } \\
\text { refinación. }\end{array}$ \\
\hline & Actores: Industria farmacéutica, de cosméticos y de alimentos: Manteca de cacao y cocoa \\
\hline & $\begin{array}{l}\text { Industria procesadora de chocolate: Chocolate para mesa, cobertura de chocolate, } \\
\text { chocolate granulado, confites, manteca de cacao, torta de cacao, licor de cacao. }\end{array}$ \\
\hline & $\begin{array}{l}\text { Principales Empresas: Compañía Bosques De Chocolate S.A., Grupo Alimenticio Alba } \\
\text { del Fonce S.A.S., Garabatos Candy Market, Café Chocolate Flor, Cocoa \& Kanela, Café } \\
\text { Colonial, Café y Chocolate Colosal, Café y Chocolate Guanenta, Chocolate San Antero, } \\
\text { Café y Chocolate Chucureño. Café y Chocolate Chucureño. El Festín Chocolatería, } \\
\text { Distribuciones César Augusto Sepúlveda, Dulce Arte, Chocolate y Café Casero Girones } \\
\text { S.A., Compañía Bosques de Chocolate S.A. }\end{array}$ \\
\hline & $\begin{array}{l}\text { Asociatividad: En Santander han existido varios intentos de organización de } \\
\text { productores de cacao que no han prosperado, hecho que se corrobora con organizaciones } \\
\text { como: ASOCAR (Asociación Cacaotera del Carare); ASOCAMI (Asociación de } \\
\text { productores de Cacao de Cimitarra); LECACAOS (Asociación de Productores de } \\
\text { Cacao de Lebrija); PLAYCACAO (Asociaci6n da Productores de Cacao del Playón), } \\
\text { RIOCACAO (Asociación de Productores de Cacao de Rionegro), PROCACAO (Asociación } \\
\text { de Productores de Cacao de Santander); ASOCASANVI (Asociación de Productores de } \\
\text { Cacao de San Vicente). }\end{array}$ \\
\hline & $\begin{array}{l}\text { Características: La industria regional posee una estructura artesanal, maquinaria } \\
\text { obsoleta de baja eficiencia y tecnología que le impide ampliar su producción, por lo que } \\
\text { ofrece básicamente chocolate de mesa a un mercado bastante limitado. }\end{array}$ \\
\hline & $\begin{array}{l}\text { Debido a la escasez de mano de obra, no se realiza adecuadamente el beneficio del } \\
\text { grano y prefiere venderlo en estado húmedo, lo que incide en la calidad final, aroma y } \\
\text { sabor, y por supuesto, en las ganancias obtenidas. }\end{array}$ \\
\hline & $\begin{array}{l}\text { - Desconocimiento de los requisitos de ingreso a mercados internacionales por parte de } \\
\text { los productores de Santander. }\end{array}$ \\
\hline & - Desconocimiento de parámetros de calidad por parte de los productores. \\
\hline & $\begin{array}{l}\text { Tecnología: El } 78,3 \% \text { de las explotaciones de cacao de Santander, poseen tecnologías } \\
\text { de producción baja, el } 22.9 \% \text { poseen tecnologías de nivel medio y menos del } 1 \% \text {, poseen } \\
\text { tecnologías altas de producción }\end{array}$ \\
\hline
\end{tabular}

Fuente: Elaboración propia. 


\section{Análisis del Eslabón de Producción de la Cadena del Cacao de Santander}

Actualmente la producción de cacao del departamento es demandada por la industria chocolatera nacional casi en su totalidad, solo un porcentaje muy bajo es exportado, y la oferta actual no satisface por completo la demanda interna por lo que se importa cacao de otros países (Lozano, Vega y Varilla, 2017).

El eslabón industrial de la Cadena se refiere a las diversas preparaciones del cacao para su comercialización dirigida al consumo final, el cacao del departamento de Santander principalmente es destinado para la fabricación de diversos productos, entre ellos tenemos, manteca de cacao, cacao en polvo, chocolate para mesa y confites con chocolate. En la Clasificación Industrial Internacional Uniforme (CIIU), a cinco (5) dígitos, los dos sub-sectores que agrupan la actividad de esta Cadena son el 31191 correspondiente a la fabricación de chocolates y preparados de Cacao y el 31192 correspondiente a la fabricación de confites con chocolate.

Las principales empresas del sector en Colombia son Compañía Nacional de Chocolates y Casa Luker y el restante entre la industria nacional está compuesta por aproximadamente 20 empresas medianas y 30 pequeñas, siendo las más destacadas Colombina S.A., Chocolate Andino, Chocolate Girones, Comestibles Italo, Tolimax, Chocolates Tumaco, entre otros. La industria chocolatera es la encargada de la transformación de los granos de cacao bajo dos modalidades, i) Subproductos de cacao, en los que se encuentran el licor de cacao, manteca de cacao y torta y ii) Producto terminado, principalmente Barras de chocolate, bombonería, coberturas, chocolate de mesa y chocolate artesanal (Contreras, 2017).

La industria procesadora realiza el proceso de tostión, descascarillado y molienda para producir licor de cacao. Una porción importante del licor se dirige a la producción de chocolates. En el caso del chocolate para mesa, el cacao molido es mezclado con mientras que, para la producción de confites o coberturas de chocolate, se mezcla el licor de cacao con azúcar, leche y manteca de cacao. El licor que no se destina a la producción de chocolate para mesa, se somete a un proceso de filtración mediante el cual se separa las tortas, o sólidos de cacao, de la manteca de cacao (líquido). Las tortas de cacao se pulverizan para darles la presentación final de "cacao en polvo" o Cocoa. La Manteca de cacao se centrifuga, atempera o cristaliza y, por último, se moldea y empaca (Montoya, Montoya y Castellanos, 2010).

En Santander se han identificado $16 \mathrm{em}$ presas procesadoras de cacao destacando Chocolate y Café Casero Girones S.A. y Grupo Alimenticio Alba del Fonce S.A.S.

TABLA 6.

Principales Cias procesadoras de Cacao (Santander).

\begin{tabular}{ll}
\hline & \multicolumn{1}{c}{ Compañía } \\
\hline 1 & Compañía Bosques de Chocolate S.A. \\
2 & Grupo Alimenticio Alba del Fonce S.A.S. \\
3 & Garabatos Candy Market \\
4 & Café y Chocolate Flor \\
5 & Cocoa \& Kanela \\
6 & Café Colonial \\
7 & Cafe y Chocolate Colosal \\
8 & Cafe y Chocolate Guanenta \\
9 & Chocolate San Antero \\
10 & Cafe y Chocolate Chucureño \\
11 & Cafe y Chocolate Chucureño \\
12 & El Festín Chocolatería \\
13 & Distribuciones César Augusto Sepúlveda \\
14 & Dulce Arte \\
15 & Chocolate y Café Casero Girones S.A. \\
16 & Compañía Bosques de Chocolate S.A. \\
\hline
\end{tabular}

Fuente: A partir de Fedecacao (2016). 


\section{- Retos del Eslabón de Producción del Cacao de Santander}

Oliveros (2013) manifiesta que Santander cuenta con buenos estándares de calidad y con el reconocimiento de la industria nacional. A pesar de ello, la industria regional posee una estructura artesanal, maquinaria obsoleta de baja eficiencia y tecnología que le impide ampliar su producción, por lo que ofrece básicamente chocolate de mesa a un mercado bastante limitado. Debido a la escasez de mano de obra, no se realiza adecuadamente el beneficio del grano y prefiere venderlo en estado húmedo, lo que incide en la calidad final, aroma y sabor, y por supuesto, en las ganancias obtenidas (Bueno, 2004). Estos aspectos plantean la necesidad de fortalecer prácticas en la cadena que promuevan la producción de un grano de mejor calidad.

Otro de los aspectos negativos del eslabón de producción de la cadena del sector cacao de Santander se encuentra que la calidad del cacao como producto final en grano seco es baja por tener establecidas operaciones de cosecha y pos cosecha con mínimo control de calidad, lo cual conduce a una heterogeneidad en el grado de fermentación (Contreras, 2017). Esta situación de baja calidad se debe en gran medida a que las operaciones de transformación del cacao en fresco, realizadas por los productores, se desarrollan de manera tradicional, tal como se ha enseñado de generación en generación. Así mismo, se han identificado falencias tecnológicas que se adapten a las condiciones de cada unidad productiva: los productores transforman distintos volúmenes de masa de cacao según épocas de cosecha y/o necesidades, desde cantidades inferiores a $10 \mathrm{~kg}$ hasta más de $400 \mathrm{~kg}$ (Fedecacao, 2004).
Se suma a lo anterior, un profundo desconocimiento de las demandas y tendencias del mercado, que conlleva a una falta de incentivo para los productores de cacao, quienes no reciben una prima económica adicional por comercializar un producto diferenciado, con valor agregado de transformación, que responda a estándares de calidad y que se caracterice por procesos rigurosos de transformación, desde la cosecha, operaciones pos cosecha (apertura de mazorca, fermentación, secado, etc.), hasta la comercialización y factores clave de la cadena como la trazabilidad, entre otras. (Barragán \& Rey, 2004)

Por otro lado, a los productores se les compra el producto sin restricciones y sin ninguna exigencia de calidad, lo que determina que el precio sea uniforme y que se desarrolle el fenómeno conocido como "circulo vicioso del modelo", donde el productor no produce con calidad debido a que esto no repercute en un mejor precio y las compañías no pagan más porque no existe calidad (Espinosa-ÁLzate y Ríos-Osorio, 2015).

\section{Análisis del Eslabón de Comercialización de la cadena agroindustrial del sector cacao de Santander}

Para realizar el análisis del eslabón de comercialización de productos de la cadena agroindustrial del sector cacao de Santander se han tomado como variables de comercialización interna y exportaciones de productos del sector.

\section{- Comercialización Interna de Cacao de Santander}

Durante del eslabón de comercialización interna del cacao se realiza la transacción económica entre el proveedor y el comercializador o intermediario, quien ayuda también como agente de calidad al revisar los 
granos de cacao para comprobar que cumple con las especificaciones de aroma, color y humedad necesarias. El Cacao deberá ser comercializado en envases que aseguren la protección del producto contra la acción de agentes externos que puedan alterar sus características químicas o físicas, y que puedan resistir las condiciones de mane- jo, transporte y almacenamiento (Perdomo, 2012).

El proceso de comercialización interna del grano en Santander tiene diferentes canales. El canal tradicional ha sido el manejado por el acopiador o intermediario, que en algunas regiones del país compra finca a finca, en otros acopia en las veredas pa-

TABLA 7

Resultado Eslabón de Producción del Cacao de Santander

Eslabón

Actividades: Procesamiento, Torrefacción, Trillado, alcalinización, Molida, Prensado, refinación.

Actores: Industria farmacéutica, de cosméticos y de alimentos: Manteca de cacao y cocoa Industria procesadora de chocolate: Chocolate para mesa, cobertura de chocolate, chocolate granulado, confites, manteca de cacao, torta de cacao, licor de cacao.

Principales Empresas: Compañía Bosques De Chocolate S.A., Grupo Alimenticio Alba Del Fonce S.A.S., Garabatos Candy Market, Café Chocolate Flor, Cocoa \& Kanela, Café Colonial, Café y Chocolate Colosal, Café y Chocolate Guanenta, Chocolate San Antero, Café y Chocolate Chucureño. Café y Chocolate Chucureño. El Festín Chocolatería, Distribuciones César Augusto Sepúlveda, Dulce Arte, Chocolate y Café Casero Girones S.A., Compañía Bosques de Chocolate S.A.

Asociatividad: En Santander han existido varios intentos de organización de productores de cacao que no han prosperado, hecho que se corrobora con organizaciones como: ASOCAR (Asociación Cacaotera del Carare); ASOCAMI (Asociación de

Eslabón productores de Cacao de Cimitarra); LECACAOS (Asociación de Productores de de Cacao de Lebrija); PLAYCACAO (Asociaci6n da Productores de Cacao del Playón), producción RIOCACAO (Asociación de Productores de Cacao de Rionegro), PROCACAO (Asociación de Productores de Cacao de Santander); ASOCASANVI (Asociación de Productores de Cacao de San Vicente).

Características: La industria regional posee una estructura artesanal, maquinaria obsoleta de baja eficiencia y tecnología que le impide ampliar su producción, por lo que ofrece básicamente chocolate de mesa a un mercado bastante limitado.

Debido a la escasez de mano de obra, no se realiza adecuadamente el beneficio del grano y prefiere venderlo en estado húmedo, lo que incide en la calidad final, aroma y sabor, y por supuesto, en las ganancias obtenidas.

Desconocimiento de los requisitos de ingreso a mercados internacionales por parte de los productores de Santander.

Desconocimiento de parámetros de calidad por parte de los productores.

Tecnología: El 78,3\% de las explotaciones de cacao de Santander, poseen tecnologías de producción baja, el $22.9 \%$ poseen tecnologías de nivel medio y menos del 1\%, poseen tecnologías altas de producción

Fuente: Elaboración propia. 
ra luego ir a comercializar la mercancía a las cabeceras municipales. Este canal es criticado por varios actores de las cadenas porque en su afán de obtener volúmenes, compran cacao de diferentes calidades, las cuales posteriormente mezclan para unificar y vender a las casas comerciales y en algunos casos a la industria (Contreras, 2017).

El Programa de Transformación productiva del Ministerio de Industria y Turismo señala que la comercialización del cacao en Santander, la comercialización de cacao se efectúa a través de cooperativas y agricultores o personas naturales acopiadoras. La cooperativa además de participar con la comercialización del cacao en grano y a diferencia de los acopiadores particulares, garantiza a los consumidores que el producto sea de la mejor calidad y es uno de los factores de regulación de precios al productor. Esto lo hace a través del puesto de compra, en donde se mueven anualmente, cierto número de toneladas de cacao en grano. De aquí en adelante las compañías compran el cacao en grano, lo transforman y lo comercializan. Las principales cooperativas cacaoteras en Santander, se encuentran en los municipios de San Vicente de Chucurí, El Carmen de Chucurí, Landázuri, Rionegro, Bucaramanga, Cimitarra, El Playón, Lebrija, Santa Helena de Opón y la Belleza (PTP, 2016).

\section{- Exportaciones de la Cadena del sector Cacao de Santander 2012-2017}

Para analizar las exportaciones de la cadena del sector cacao se ha tomado como referencia al capítulo arancelario número 18 correspondiente al cacao y sus derivados. Para realizar este análisis se estableció como fuente de consulta el Sistema Estadístico de Comercio Exterior (SIEX) del
Departamento de Impuestos y Aduanas Nacionales (DIAN) tomando como referencia las exportaciones durante los años 2012 y 2017.

De acuerdo a cifras proporcionadas por el SIEX las exportaciones del capítulo arancelario número 18 , se ha venido desarrollando en el periodo 2012-2016 como muestra la Tabla 8.

En la Tabla 8 se presentan las ventas internacionales del capítulo arancelario No. 18 donde se puede percibir que el mejor comportamiento de esta variable se desarrolló entre los años 2014 y 2016. El año 2015 que se encuentra resaltado en la tabla anterior es el año con mejores exportaciones en el periodo estudiado alcanzando un record histórico de exportaciones con ventas por valor de US\$20.862.213 y alcanzando su mayor participación en las exportaciones del país aportando el 16\% de las exportaciones totales de Colombia. Esta misma tendencia positiva en las exportaciones en los años 2014 y 2016 alcanzando una participación superior al 8\% en las ventas totales internacionales del grano de Colombia.

En cuanto a la tipología de los productos que se exportaron en la cadena agroindustrial de cacao entre los años 2012 y 2017 el departamento se limitó a cuatro productos Demás cacaos crudos o enteros con una participación entre el 99\% y 100\% en los años de estudio. De igual forma, se registra una mínima participación de otros subcapítulos arancelarios como: Demás chocolates sin edición de azúcar; Pasta de cacao sin desgrasar y Demás chocolates sin edición de azúcar con una participación por debajo del $1 \%$.

En cuanto a los mercados de destino es de destacar la poca continuidad que se presenta en la consolidación de mercados de exportación de Santander. Por ejemplo, 
TABLA 8.

Exportaciones Santander Cacao 2012-2016.

\begin{tabular}{|c|c|c|c|c|c|}
\hline Año & $\begin{array}{l}\text { Peso Neto } \\
\quad(\mathrm{Kg})\end{array}$ & Valor US\$ & Principales Productos & Destinos & $\begin{array}{c}\text { \% de } \\
\text { Participación en } \\
\text { las X nacionales }\end{array}$ \\
\hline 2012 & 1.008 .315 & 2.554 .763 & $\begin{array}{l}\text {-Demás cacaos en crudo o } \\
\text { en grano } 99,3 \% \text {, } \\
\text { - Demás chocolates sin } \\
\text { edición de azúcar } 0,7 \%\end{array}$ & $\begin{array}{ll}\text { - } & \text { Turquía } \\
& 35,8 \% \\
\text { - } & \text { Italia } 22,1 \%, \\
\text { - } & \text { India } 19,6 \% .\end{array}$ & $5.2 \%$ \\
\hline 2013 & 2.859 .568 & 6.870 .565 & $\begin{array}{l}\text { - Demás cacaos en crudo o } \\
\text { en grano } 99,9 \% \text {, } \\
\text { - Demás preparaciones } \\
\text { alimenticias que contengan } \\
\text { cacao } 0,1 \% \text {. }\end{array}$ & 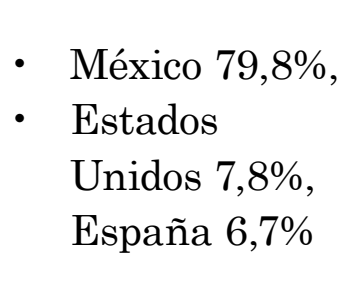 & $6.7 \%$ \\
\hline 2014 & 3.900 .758 & 11.772 .779 & $\begin{array}{l}\text { Demás cacaos crudos o } \\
\text { enteros } 100 \%\end{array}$ & 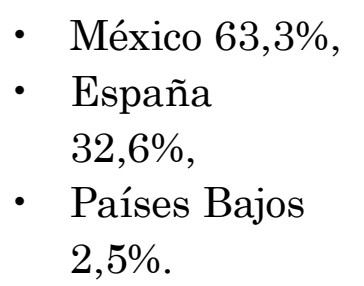 & $8.06 \%$ \\
\hline 2015 & 6.938 .039 & 20.862 .213 & $\begin{array}{l}\text { - Demás cacaos crudos o } \\
\text { enteros } 99,9 \% \\
\text { - Pasta de cacao sin } \\
\text { desgrasar } 0,1 \%\end{array}$ & $\begin{array}{ll}\text { - } & \text { México } 34,2 \% \\
\text { - } & \text { Malasia } 30,6 \%\end{array}$ & $16 \%$ \\
\hline 2016 & 5.564 .797 & 16.512 .697 & Cacao Crudo o enteros & $\begin{array}{l}\text { - } \text { Malasia } 24,1 \% \\
\text { - } \quad \text { España } 22,8 \%\end{array}$ & $8.6 \%$ \\
\hline 2017 & 3.000 .080 & 8.800 .000 & $\begin{array}{l}\text { Demás cacaos crudos o } \\
\text { enteros } 100 \%\end{array}$ & $\begin{array}{l}\text { - } \quad \text { México } 53,6 \% \\
\text { - España } 19,3 \%\end{array}$ & $3,6 \%$ \\
\hline
\end{tabular}

Fuente: Elaboración propia a partir de SIEX (DIAN).

se puede apreciar que las exportaciones del capítulo 18 tenían como destino a Turquía en el año 2012 con un 35,8\% de participación en las mismas y en los años posteriores las ventas hacia ese mercado desaparecen. Sucede lo mismo con los mercados de Italia, India Estados Unidos, Países Bajos. Los únicos mercados que tienen continuidad en las exportaciones del capítulo 18 de Santander en el periodo 2012-2017 son los de México, Malasia y España.

Finalmente, es importante de igual forma destacar la caída que se registra en el año 2016 y 2017 con una considerable reducción en las ventas internacionales.
Componente socio empresarial del Sector Agroindustrial del Cacao de Santander

Fedecacao es la institución que agremia a los productores de cacao, administra el Fondo Nacional del Cacao y el Fondo de Estabilización de Precios de Cacao. Interviene en: Asistencia Técnica y Transferencia de Tecnología, capacitación, escuelas de campo; investigación y comercialización

Las siguientes entidades presentadas en la Tabla 10 corresponden a instituciones gremiales y entidades estatales, gubernamentales y no gubernamentales, que buscan apoyar técnica o financieramente a los 
TABLA 9.

Resultados Eslabón de Comercialización de la cadena agroindustrial del sector cacao de Santander.

Comercialización Interna:

Actividades: Transporte, distribución y Comercialización

Actores: Asociaciones, acopiadores, comisionistas, exportadores.

Características: comercialización de cacao se efectúa a través de cooperativas y agricultores

Eslabón o personas naturales acopiadoras.

de co- $\quad$ Las principales cooperativas cacaoteras en Santander, se encuentran en los municipios

mercia- de San Vicente de Chucurí, El Carmen de Chucuri, Landázuri, Rionegro, Bucaramanga,

lización Cimitarra, El Playón, Lebrija, Santa Helena de Opón y la Belleza.

Comercialización Externa:

Principal Producto de Exportación; Demás cacaos en crudo o en grano, Demás chocolates sin edición de azúcar; Pasta de cacao sin desgrasar y Demás chocolates sin edición de azúcar Principales Mercados: México, Malasia y España.

Fuente: Elaboración propia.

TABLA 10.

Entidades Socio Empresariales de la Cadena Agroindustrial de Santander.

\begin{tabular}{|c|c|}
\hline Entidad & Definición \\
\hline Fedecacao & $\begin{array}{l}\text { La Federación Nacional de Cacaoteros es una Asociación Nacional de carácter gremial, } \\
\text { de derecho privado, sin ánimo de lucro, integrada por los productores de cacao dentro } \\
\text { del territorio de la República de Colombia que manifiesten el deseo de pertenecer a la } \\
\text { misma. Las entidades aceptadas deben cumplir los estatutos, normas y procedimientos } \\
\text { establecidos por los órganos de dirección, administración, control y vigilancia de la } \\
\text { Federación. Es la administradora del Fondo Nacional del Cacao }\end{array}$ \\
\hline $\begin{array}{l}\text { Cooperativa } \\
\text { Eco cacao }\end{array}$ & $\begin{array}{l}\text { Es una organización empresarial asociativa sin ánimo de lucro conformada por familias } \\
\text { campesinas vinculadas a la actividad agropecuaria y personas conectadas a dicha } \\
\text { actividad en diferentes eslabones de la cadena productiva. Tiene como objeto central } \\
\text { "contribuir al mejoramiento social y económico de los asociados" (ECOCACAO), para lo } \\
\text { cual presta servicios estratégicos para el desarrollo agropecuario. }\end{array}$ \\
\hline Aproc & $\begin{array}{l}\text { Es una entidad de carácter agropecuario, sin ánimo de lucro, abierta a todos los } \\
\text { productores de cacao sin distinción de raza, credo o afiliación política. Se rige de acuerdo } \\
\text { con la Constitución Política de Colombia, las leyes y los estatutos propios. }\end{array}$ \\
\hline Finagro & $\begin{array}{l}\text { El fondo para el financiamiento del Sector Agropecuario, fue creado por la Ley } 1 \text { de } 1990 \\
\text { y nace de la necesidad del sector agropecuario y rural de contar con un Sistema Nacional } \\
\text { de Crédito Agropecuario. Es una entidad autónoma especializada en manejar los recursos } \\
\text { de crédito dispersos en varios organismos y representa una variante complementaria de } \\
\text { la política macro económica de la Junta Directiva del Banco de la Republica. }\end{array}$ \\
\hline CORPOICA & $\begin{array}{l}\text { La Corporación Colombiana de Investigación Agropecuaria, es una entidad pública } \\
\text { descentralizada con régimen privado, encargada de generar conocimiento científico y } \\
\text { soluciones tecnológicas a través de actividades de investigación, innovación, transferencia } \\
\text { de tecnología y formación de investigadores, en pro del sector agropecuario colombiano. }\end{array}$ \\
\hline $\begin{array}{l}\text { Fondo } \\
\text { Nacional } \\
\text { del Cacao }\end{array}$ & $\begin{array}{l}\text { El Fondo Nacional del Cacao fue creado mediante Ley } 67 \text { de diciembre } 30 \text { de } 1983 \text {, } \\
\text { reglamentada con el Decreto } 1000 \text { de } 1984 \text {, definiéndolo como una Cuenta Especial para } \\
\text { el recaudo y manejo de los recursos provenientes de la Cuota de fomento Cacaotero, cuyo } \\
\text { propósito es la financiación de programas y proyectos de beneficio para la actividad cacao } \\
\text { cultora nacional }\end{array}$ \\
\hline
\end{tabular}

Fuente: Elaboración propia a partir de Perdomo (2012). 
cacaoteros, para regular y promocionar el cacao. Estas organizaciones incluyen: federaciones nacionales, cooperativas, entidades reguladoras, cooperativas, gremios de cacaoteros, entre otras. A continuación, se describen algunas de estas organizaciones mostrando así el caso santandereano.

Componente entorno-infraestructura de la Cadena del Sector Agroindustrial del Cacao de Santander

Para analizar el componente entorno infraestructura de la cadena del sector cacao de Santander se tomó como referencia el estado de la Infraestructura Vial. Los autores de esta investigación consideran que para la consolidación de la cadena agroindustrial del Cacao de Santander se deben tener como prioridad el mejoramiento de infraestructura para facilitar las interacciones comerciales de Santander con otros departamentos, para disminuir los costos de traslado del grano y para evitar la presencia de intermediarios.

En condiciones generales Santander cuenta con una infraestructura promedio, donde se puede evidenciar que las vías pavimentadas a pesar de estar en buen estado deben mejorar y estar acordes a las necesidades de la población, pues aun cuenta con vías sin pavimentar lo cual afectar de manera significativa la competitividad del departamento, ya que los accesos a las vías para el transporte del Cacao en ocasiones se ven afectadas por las condiciones climáticas. En ese mismo sentido Oliveros (2013) señala que el estado de las vías para sacar el producto de las fincas y de los pueblos es muy defectuoso, generalmente se ven afectadas por el invierno, existen zonas donde los productores los últimos años se han tenido que quedar con los productos en sus fincas, a falta de caminos por donde sacarlos. Las vías que se ven más afecta- das son las que de San Vicente conducen a Barrancabermeja, el Carmen de Chucurí y Bucaramanga, además de los carreteables que comunican al municipio con sus diferentes veredas (Oliveros, 2013).

Las vías de acceso más utilizadas son San Vicente que conduce a Barrancabermeja, el Carmen de Chucuri y Bucaramanga. El Gobierno a través del Plan Nacional Desarrollo tiene la ejecución de las siguientes rutas, la Zona Metropolitana de Bucaramanga (2006-2027) con una inversión de 0.3 billones de pesos equivalente a $58.3 \mathrm{~km}$. El programa de Transformación Productiva, junto con el Ministerio de Comercio, Industria y Turismo y el Ministerio de Agricultura y Desarrollo Rural, están implementando planes de desarrollo sectorial, con el fin de fomentar de manera efectiva la infraestructura para orientar al sector a ser más productivo (Acuerdos de Competitividad de la Cadena del Cacao y su Agroindustria 2009-2022).

\section{Matriz General de la Minicadena de Cacao en el departamento de Santander}

Para construir la matriz de la minicadena del cacao del departamento de Santander se realizó un estudio de cada uno de los eslabones de cadena agroindustrial del sector cacao analizando las variables presentadas anteriormente por eslabón. El resultado de la matriz 4 a juicio de los autores de este artículo es el principal aporte que le hace esta investigación a la literatura escrita sobre la temática de la cadena del cacao.

A continuación, se presenta el resultado de la matriz general con sus cinco componentes principales: materias primas e insumos; producción; comercialización; Componente socio empresarial y componente entorno-infraestructura (Tabla 11). 
TABLA 11

Modelo de la Minicadena de Cacao en el departamento de Santander

\begin{tabular}{|c|c|}
\hline Eslabón & Análisis \\
\hline \multirow{18}{*}{$\begin{array}{l}\text { Eslabón de } \\
\text { materias primas } \\
\text { e insumos: }\end{array}$} & Actividades: \\
\hline & Estos son los pasos a seguir para la obtención del grano de cacao: \\
\hline & $\begin{array}{l}\text { Análisis del suelo, control de malezas, manejo de Sombra, plan de } \\
\text { fertilización, la poda, control fitosanitario, recolección de mazorca } \\
\text { maduras, partida de la mazorca, desgranado, fermentación, secado, } \\
\text { clasificación con Zaranda, empacado en sacos de fique. }\end{array}$ \\
\hline & Zona Productora: \\
\hline & La zona productora de cacao se encuentra localizada en la Montaña \\
\hline & Santandereana, Vertiente Occidental de la Cordillera Oriental, que \\
\hline & recorre al departamento de sur a norte, bordeando el valle del río \\
\hline & Magdalena. En esta subregión, se encuentran localizados, Landázuri, \\
\hline & El Carmen, San Vicente, Rionegro, El Playón y Lebrija \\
\hline & Actores: \\
\hline & $\begin{array}{l}\text { Dueños de tierras, agricultores, productores de insumos. Productores } \\
\text { pequeños y medianos } 98 \% \text {. Predomina el pequeño y mediano productor, } \\
\text { de economía campesina, con escasos recursos especialmente de capital e } \\
\text { infraestructura para la producción. }\end{array}$ \\
\hline & Proveedores: \\
\hline & $\begin{array}{l}\text { Los proveedores de insumos en la cadena se clasifican en dos grandes } \\
\text { grupos: los proveedores de insumos para el cultivo, donde se encuentran } \\
\text { aquellos comercializadores de material vegetal, agroquímicos y } \\
\text { pesticidas, y los proveedores de herramientas y equipo para el } \\
\text { cultivo del cacao en las fincas; y por otro lado se encuentran aquellos } \\
\text { proveedores de insumos y materias primas para la agroindustria } \\
\text { dedicada a la transformación }\end{array}$ \\
\hline & Insumos Específicos: \\
\hline & $\begin{array}{l}\text { Material vegetal, agroquímicos y pesticidas; herramientas y equipo } \\
\text { para el cultivo del cacao y para la transformación. }\end{array}$ \\
\hline & $\begin{array}{l}\text { Los principales son fertilizantes como la urea, triple } 15 \text { tradicional y } \\
\text { cafetero, DAP; entre otros, con precios que oscilan desde los } \$ 54.000 / \\
\text { bulto hasta los } \$ 95.000 / \text { bulto; el siguiente grupo de productos } \\
\text { demandados son los cicatrizantes de podas, tales como cal dolomita, } \\
\text { pasta cicatrizante, oxicloruro de cobre, entre otros ,con precios que } \\
\text { varían desde los } \$ 7.500 / \mathrm{kg} \text { hasta los } \$ 23.000 / \mathrm{kg} \text {; en tercer grupo se } \\
\text { encuentras los herbicidas, fungicidas e insecticidas, donde se resalta el } \\
\text { uso de glifosato. }\end{array}$ \\
\hline & Eslabón: \\
\hline & $\begin{array}{l}\text { Mano de obra intensiva de baja calificación y configura una explotación } \\
\text { típica de economía campesina; Tecnología baja. }\end{array}$ \\
\hline
\end{tabular}




\begin{tabular}{|c|c|}
\hline Eslabón & Análisis \\
\hline $\begin{array}{l}\text { Eslabón de } \\
\text { producción }\end{array}$ & $\begin{array}{l}\text { Actividades: } \\
\text { Procesamiento, Torrefacción, Trillado, } \\
\text { alcalinización, Molida, Prensado, refinación. } \\
\text { Actores: } \\
\text { Industria farmacéutica, de cosméticos y de alimentos: Manteca de cacao } \\
\text { y cocoa } \\
\text { Industria procesadora de chocolate: } \\
\text { Chocolate para mesa, cobertura de chocolate, chocolate granulado, } \\
\text { confites, manteca de cacao, torta de cacao, licor de cacao. } \\
\text { Principales Empresas: } \\
\text { Compañía Bosques de Chocolate S.A., Grupo Alimenticio Alba del } \\
\text { Fonce S.A.S., Garabatos Candy Market, Café Chocolate Flor, Cocoa } \\
\text { \& Kanela, Café Colonial, Café y Chocolate Colosal, Café y Chocolate } \\
\text { Guanenta, Chocolate San Antero, Café y Chocolate Chucureño. Café } \\
\text { y Chocolate Chucureño. El Festín Chocolatería, Distribuciones César } \\
\text { Augusto Sepúlveda, Dulce Arte, Chocolate y Café Casero Girones S.A., } \\
\text { Compañía Bosques de Chocolate S.A. } \\
\text { Asociatividad: } \\
\text { En Santander han existido varios intentos de organización de } \\
\text { productores de cacao que no han prosperado, hecho que se corrobora } \\
\text { con organizaciones como: ASOCAR (Asociación Cacaotera del Carare); } \\
\text { ASOCAMI (Asociación de productores de Cacao de Cimitarra); } \\
\text { LECACAOS (Asociación de Productores de Cacao de Lebrija); } \\
\text { PLAYCACAO (Asociaci6n da Productores de Cacao del Playón), } \\
\text { RIOCACAO (Asociación de Productores de Cacao de Rionegro), } \\
\text { PROCACAO (Asociación de Productores de Cacao de Santander); } \\
\text { ASOCASANVI (Asociación de Productores de Cacao de San Vicente). } \\
\text { Características: } \\
\text { La industria regional posee una estructura artesanal, maquinaria } \\
\text { obsoleta de baja eficiencia y tecnología que le impide ampliar su } \\
\text { producción, por lo que ofrece básicamente chocolate de mesa a un } \\
\text { mercado bastante limitado. Debido a la escasez de mano de obra, no } \\
\text { se realiza adecuadamente el beneficio del grano y prefiere venderlo en } \\
\text { estado húmedo, lo que incide en la calidad final, aroma y sabor, y por } \\
\text { supuesto, en las ganancias obtenidas. } \\
\text { Desconocimiento de los requisitos de ingreso a mercados } \\
\text { internacionales por parte de los productores de Santander. } \\
\text { Tecnología: } \\
\text { El 78,3\% de las explotaciones de cacao de Santander, poseen tecnologías } \\
\text { de producción baja, el 22.9\% poseen tecnologías de nivel medio y menos } \\
\text { del 1\%, poseen tecnologías altas de producción. }\end{array}$ \\
\hline
\end{tabular}




\begin{tabular}{|c|c|}
\hline Eslabón & Análisis \\
\hline $\begin{array}{l}\text { Eslabón de } \\
\text { comercialización }\end{array}$ & $\begin{array}{l}\text { Comercialización Interna: } \\
\text { Actividades: Transporte, distribución y Comercialización } \\
\text { Actores: Asociaciones, acopiadores, comisionistas, exportadores. } \\
\text { Características: comercialización de cacao se efectúa a través de } \\
\text { cooperativas y agricultores o personas naturales acopiadoras. } \\
\text { Las principales cooperativas cacaoteras en Santander, se encuentran } \\
\text { en los municipios de San Vicente de Chucurí, El Carmen de Chucuri, } \\
\text { Landázuri, Rionegro, Bucaramanga, Cimitarra, El Playón, Lebrija, } \\
\text { Santa Helena de Opón y la Belleza. } \\
\text { Comercialización Externa: } \\
\text { Principal Producto de Exportación; Demás cacaos en crudo o en grano, } \\
\text { Demás chocolates sin edición de azúcar; Pasta de cacao sin desgrasar y } \\
\text { Demás chocolates sin edición de azúcar } \\
\text { Principales Mercados: } \\
\text { México, Malasia y España. }\end{array}$ \\
\hline $\begin{array}{l}\text { Componente } \\
\text { socio empresarial }\end{array}$ & $\begin{array}{l}\text { Las principales instituciones que trabajan por el sector son: Fedecacao, } \\
\text { Cooperativa Ecocacao, Aprocasur, Finagro, Corpoica Fondo Nacional } \\
\text { del Cacao, Cámara de Comercio de Bucaramanga, Clúster del Cacao, }\end{array}$ \\
\hline $\begin{array}{l}\text { Componente } \\
\text { entorno- } \\
\text { infraestructura }\end{array}$ & $\begin{array}{l}\text { Las vías de acceso más utilizadas son San Vicente que conduce a } \\
\text { Barrancabermeja, el Carmen de Chucuri y Bucaramanga en ocasiones } \\
\text { se ven afectadas por las condiciones climáticas }\end{array}$ \\
\hline
\end{tabular}

Fuente: Elaboración propia a partir de ONUDI, 2004.

En virtud del análisis realizado a lo largo de la investigación, se pudo determinar que el sector cacaotero del departamento de Santander no ha logrado integrar adecuadamente las ventajas comparativas con dinámicas sociales y empresariales sobresalientes que promuevan la generación de valor. Por ello, este artículo ha buscado establecer las particularidades que hacen del cultivo del cacao una actividad económica importante que aún no ha logrado consolidarse bajo la dinámica de una cadena productiva.

El cacao de Santander como actividad presenta problemas de competitividad en la medida en que las prácticas realizadas por los agricultores no son las adecuadas para generar mayores rendimientos y buena calidad de grano. Adicionalmente, las variables que explican la disminución de la producción también están sustentadas en el envejecimiento de los cultivos, la falta de mejoramiento genético, la presencia creciente de enfermedades y la falta de capital humano que permita una mayor transferencia de tecnología. Sobre este particular, FEDECACAO afirma que las personas que más tiempo dedican al cultivo son las personas mayores, con edades entre 51 a 65 años (Alarcón y Perilla, 2016).

Asimismo, se resalta la baja tecnología usada en el sector, donde según cálculos realizados por Pabón, Herrera-Roa y Sepúlveda (2016), aproximadamente el 78,3\% de las explotaciones de cacao de Santander, poseen tecnologías de producción baja, el $22.9 \%$ poseen tecnologías de nivel medio y menos del 1\%, poseen tecnologías altas de 
producción, Asimismo, se ha identificado que el manejo post-cosecha de los granos de cacao en la finca productora, posee cierto letargo tecnológico. Las explotaciones de cacao del país son tradicionales y de economía campesina, donde las actividades productivas se reducen a labores básicas demandando gran mano de obra (Pabón, Herrera-Roa y Sepúlveda, 2016).

A pesar de este resultado poco alentador de la cadena agroindustrial del sector cacao de Santander en esta sección final se presentan las perspectivas de esta cadena para los próximos años en marco de la estrategia de desarrollo regional del gobierno colombiano para el periodo de pos conflicto. Esto implica mayor asistencia técnica por parte de entidades públicas y privadas para incrementar la producción de cacao de alta calidad para una mayor competitividad.

\section{Consideraciones Finales}

Este artículo pretende contribuir a la literatura existente en la temática de las cadenas agroindustriales en Colombia proporcionando un análisis sobre las oportunidades de las cadenas del departamento de Santander y su posible inmersión a cadenas internacionales en el marco de la búsqueda de oportunidades de empleo y desarrollo en las regiones afectadas por el conflicto colombiano. De igual forma el interés de los investigadores de este proyecto fue generar insumos prácticos y conceptuales que coadyuven para que la apuesta productiva del cacao trascienda hacia dinámicas de competitividad territorial y desarrollo regional en el pos conflicto.

El proceso investigativo que aquí se presenta se ha concentrado en identificar las razones por las cuales, a pesar de la existencia de condiciones naturales favorables, de contar con una excelente clasificación y con el reconocimiento por la variedad y la calidad del cacao que se produce, esta actividad económica no ha logrado posicionarse como un sector productivo predominante dentro de la estructura económica del departamento de Santander. En la sección final, a continuación se presentan las más importantes estrategias desarrolladas por el gobierno nacional y la comunidad internacional, las cuales pueden ser la plataforma de acceso para empresas del sector cacao de Santander a cadenas globales de valor destacándose el programa Cacao para la Paz, el proyecto de Promoción de la Producción y Exportación de Cacao Fino y de Aroma en Colombia", del Programa Suizo de cooperación al desarrollo económico en Colombia (SECO) y la conformación del clúster del cacao.

\section{El Cultivo de la Paz y Cooperación Internacional}

El departamento de Santander es considerado en gran proporción zona de posconflicto debido a que en su territorio contaba con gran presencia de las FARC, así como también de grupos paramilitares, aun así, históricamente ha sido el departamento con mayor aporte a la producción nacional del grano, por lo que se considera que, con el fin del conflicto armado en el país, este departamento presente una gran proyección en cuanto a la producción de cacao se refiere (Hernández, Chumaceiro, Ziritt y Acurero, 2018).

Teniendo en cuenta lo anterior, se puede señalar que el cultivo de cacao tiene un alto potencial para generar crecimiento económico en el departamento de Santander, al ser este cultivo una alternativa viable para reemplazar cultivos ilícitos. Este es un momento propicio para que el departamento de Santander aumente su productividad y se 
generen oportunidades para la intensificación de la producción de cacao. Dada la actual situación libre de conflicto armado en los campos de este departamento los campesinos pueden retornar a sus cultivos y reactivar su productividad, actualmente solo el 20\% de la superficie de las fincas agrícolas del departamento están destinadas al cacao, las posibilidades de expansión son muy altas dado que alrededor del 63\% de los suelos de las fincas Santandereanas están siendo subutilizadas en rastrojos y pasturas (Torres-De la Cruz, Ortiz-García, Bautista-Muñoz, Ramírez-Pool, Ávalos-Contreras, Cappello-García y De la Cruz-Pérez, 2015).

Tomando en cuenta estas oportunidades, el gobierno colombiano y la comunidad internacional han venido buscando alternativas en el programa de sustitución de cultivos ilícitos, donde se busca remplazar las plantaciones de coca por cultivos productivos como el plátano, el café y el cacao, como opción productiva y laboral para los excombatientes y desplazados. La importancia del cultivo del cacao en esta estrategia se pudo evidenciar en el discurso pronunciado por el Presidente Juan Manuel Santos en agosto del 2016 donde se refirió al cacao como el 'cultivo de la Paz', afirmando que este cultivo será fundamental en el posconflicto frente a las grandes posibilidades que tiene en la sustitución de cultivos ilícitos y su potencial para aportar al crecimiento de la economía del país (El Tiempo, 2017).

\section{“Cacao para la Paz”}

De acuerdo a Sierra (2016)," Cacao por la paz" se visualiza como uno de los proyectos líderes en el tema de reforma agraria y sustitución de cultivos ilícitos en esta nueva historia que está escribiendo Colombia, en donde tiene claro que para poder abordar el tema de raíz y erradicar el gran problema tiene que empezar desde su punto de fuerza y equilibrio que es el campo y por consiguiente contar con diferentes programas que proporcionen desarrollo y sostenibilidad ambiente,

El Cacao ha sido promovido como el cultivo del post-conflicto pues desde diferentes organizaciones internacionales y agencias de cooperación internacional se ha propuesto su siembra, como cultivo para sustituir las plantaciones ilegales de coca. La Cooperación Internacional está interesada en realizar proyectos que ayuden en el posconflicto y que tengan relación con el cacao, uno de los más importantes es "Cacao por la Paz" implementado por la agencia de Cooperación Internacional de Estados Unidos (USAID). Según el gobierno colombiano la inversión a este proyecto va a generar grandes beneficios en el proceso de desarme, desmovilización y reinserción por parte de las FARC; evidenciando así una inclusión social con la que se busca mejor calidad de vida que genere sostenibilidad. Es una alternativa de gran importancia ya que no solo va a contribuir de gran manera al proceso de posconflicto, sino que a su vez va a generar desarrollo productivo y económico al departamento (Sierra, 2016).

Estas nuevas iniciativas por parte de la cooperación internacional generan en la población luces de esperanza para un cambio en donde saben que no se encuentran solos y que para este proceso van a estar acompañados y apoyados no solo por actores gubernamentales locales; sino que también por la comunidad internacional. Esta Cooperación Internacional quiere brindar oportunidad a las personas en condición de vulnerabilidad que han sido fuertemente golpeadas y marcadas socialmente por la guerra, para brindarles nuevos nichos de negocio $u$ opciones de cambio. Los principales objetivos de la ayuda internacional que recibe el país 
es aumentar las condiciones de oportunidades y poder obtener el mayor beneficio para generar cambios positivos en las circunstancias de vida, como se puede evidenciar en este proyecto que quiere implementar nuevas prácticas para la trasformación y cambio del campo en el país, partiendo de que es una de las principales fuentes de ingreso con las que contamos.

Para USAID la transformación del campo es un punto clave para aportar progreso al país, gracias a la iniciativa nace este programa que busca una inclusión social en donde se "apoya a familias, comunidades y organizaciones campesinas, indígenas o afrocolombianas, ubicadas en ecosistemas ambientales estratégicos y en zonas de frontera agrícolas que se hayan visto afectadas o estén amenazadas por los cultivos ilícitos y que deseen erradicarlos y adelantar alternativas" (Oficina de las Naciones Unidas contra la Droga y el Delito-UNODC, 2016). De esta manera quieren que los campesinos pasen de una acción económica ilegal a una legal en donde podrán tener todas las garantías y apoyo para un cambio de actividad que traerá paz.

Proyecto de Promoción de la Producción y Exportación de Cacao Fino y de Aroma en Colombia" (COEXA), del Programa Suizo de Cooperación al Desarrollo Económico en Colombia (SECO)

El Proyecto de Promoción de la Producción y Exportación de Cacao Fino y de Aroma en Colombia" (COEXCA) es un proyecto del Programa Suizo de Cooperación al Desarrollo Económico en Colombia (SECO) que fue encargado a Swisscontact para su ejecución, como uno de los tres proyectos de construcción de capacidades de comercio que Suiza acordó implementar en Colombia, en el marco del TLC entre ambos países en
2011. Desde entonces, el proyecto ha buscado posicionar los Cacaos Especiales colombianos- ampliando la categoría de cacao fino de aroma (CAF)-, como un producto de calidad reconocida y confiable en el mercado internacional (Escobar, 2017).

Coexca ha acompañado iniciativas que desde lo público buscan también impulsar la cadena de cacao fino y de aroma y más ampliamente, la de cacaos especiales. En convenio con el Ministerio de Comercio Industria y Turismo (Procolombia y el Programa de Transformación Productiva), el proyecto ha realizado acciones para fortalecer la competitividad y el posicionamiento del sector y, a través de su ejecutor Swisscontact, ha tomado y sigue tomando parte activa de la Alianza Cacaotera, una iniciativa que reúne a diversos actores privados y públicos y que discute las agendas relacionadas con la productividad, la comercialización y la investigación del sector (Escobar, 2017).

\section{Clúster del Cacao de Santander}

La Cámara de Comercio de Bucaramanga, es líder en la implementación de estrategias clúster en Santander, involucrando diferentes sectores empresariales, con el objetivo de fortalecer y fomentar la competitividad de la región.

Desde el año 2016 la Cámara de Comercio de Bucaramanga conjuntamente con los actores de la cadena agroindustrial de Santander han venido trabajando en el proyecto de implementación del clúster del cacao en Santander (Cámara Directa, 2016). Este proyecto tiene principalmente dos líneas de acción: En la primera de ellas se trabaja con cacao en grano, donde se presta apoyo a la cadena en: Manejo agrícola especial y desarrollo de infraestructura; Marketing territorial; conocimiento de mercado y cer- 
tificaciones; Fortalecimiento del talento humano; Plataforma de compradores. La segunda línea de acción tiene que ver con el Cacao Transformado, donde se presta apoyo a la cadena en el desarrollo del conocimiento de mercados internacionales; Investigación, innovación y desarrollo de productos; Integración y promoción en canales de comercialización.

Con los programas anteriormente presentados, es posible afirmar que Santander y en general los departamentos dedicados al cultivo de cacao en el país, cuentan con un escenario propicio para el aprovechamiento de incentivos. A través del apoyo de entidades públicas y privadas, se deben establecer estrategias enfocadas en el mejoramiento de los procesos productivos asociados al cultivo del cacao, capacitación y especialización de campesinos e inversión en infraestructura adecuada para el cultivo y el traslado de las toneladas de grano producidas, también se debe priorizar la inversión en investigación para desarrollar alternativas a problemáticas de tipo climático y fitosanitario.

Todo lo anterior, se debe ver representado en el mejoramiento de la calidad del grano producido, mejores prácticas por parte de los campesinos, los cuales también deben percibir mejores ingresos por sus cosechas y a su vez un mejoramiento en su calidad de vida, no solamente por la ausencia de grupos armados en el campo sino también porque en la medida en que el cultivo de cacao sea más competitivo el sector rural deberá ser también más atractivo para vivir y trabajar.

\section{Conclusiones}

Del estudio presentado anteriormente sobre el análisis de la cadena agroindustrial del sector cacao de Santander se pueden destacar los siguientes cinco aspectos fundamentales de esta investigación:

- El sector cacao del departamento de Santander no ha logrado promover la generación de valor en la cadena de valor debido al bajo desarrollo tecnológico en las operaciones de transformación, el desconocimiento de los parámetros de calidad por parte de los eslabones de productores y comercializadores, el desconocimiento de los requisitos de los mercados internacionales y los problemas de asociatividad, confianza e integración de los eslabones de la cadena. Como respuesta a las debilidades anteriormente planteadas, las políticas públicas de Colombia han priorizado al cacao como materia prima de interés para el desarrollo rural, desplegando acciones gubernamentales y de cooperación internacional encaminadas a consolidar una adecuada cadena de valor y de esa forma solventar las necesidades tecnológicas y organizativas de un sector agrícola clave en el proceso de sustitución de cultivos ilícitos en el pos conflicto.

- El cultivo del cacao se registra en 42 municipios del departamento de Santander. Sin embargo, el 80\% de las áreas cosechadas y la producción de la cadena agroindustrial del sector cacao se limita a cinco municipios. El más importante de ellos es San Vicente De Chucuri con una producción de 6,302 toneladas en el año 2017, lo sigue muy de cerca El Carmen de Chucuri con 6,096 toneladas, y con menor producción Landázuri con 2,854, Rionegro con 2,699 y Cimitarra con 1,004 Toneladas registradas en el año 2017. El resto de municipios presentan cifras inferiores a las 500 toneladas en el año 2017. 
- Las exportaciones de la cadena agroindustrial de cacao entre los años 2012 y 2017 del departamento de Santander se limitaron a cuatro productos Demás cacaos crudos o enteros con una participación entre el 99\% y 100\% en los años de estudio. De igual forma, se registra una mínima participación de otros subcapítulos arancelarios como: Demás chocolates sin edición de azúcar; Pasta de cacao sin desgrasar y Demás chocolates sin edición de azúcar con una participación por debajo del 1\%. En cuanto a los mercados de destino se destacan México, Malasia y España.

- Los productores de cacao del departamento de Santander tienen muchas oportunidades en el periodo del pos conflicto colombiano de ingresar a cadenas globales de valor al haber sido priorizado por el gobierno nacional como uno de los productos agropecuarios con mayor potencial, gracias al reconocimiento mundial de la calidad de los genotipos que se cultivan en Santander, con lo cual pudiera posicionarse en el nicho de cacaos especiales.

- El Cacao ha sido promovido como el cultivo del post-conflicto pues desde diferentes organizaciones internacionales y agencias de cooperación internacional se ha propuesto su siembra, como cultivo para sustituir las plantaciones ilegales de coca. La Cooperación Internacional está interesada en realizar proyectos que ayuden en el posconflicto y que tengan relación con el cacao, uno de los más importantes es "Cacao por la Paz" implementado por la agencia de Cooperación Internacional de Estados Unidos (USAID).

\section{REFERENCIAS}

Alarcón, J. y Perilla, L. X. (2016). Agro cadenas: Vigilancia tecnológica de los tres principales productos agrícolas base de alimentación y cultivados en cada uno de los países, objeto de estudio. (Doctoral dissertation). Universidad del Rosario, Bogotá, Colombia.

Barragán, A. y Rey, L. C. (2004). Establecimiento de núcleos productivos de cacao (Theobroma cacao) en torno a micro centrales de beneficio para mejorar la calidad del grano en la región del distrito agroindustrial de la magdalena caldense. [Doctoral dissertation]. Universidad Nacional de Colombia, Manizales, Colombia.

Bonilla, E., Cardeño, E. y Cardeño, N. (2015). La función financiera en las micros, pequeñas y medianas empresas, del municipio de Riohacha. Económicas CUC, 36(2), 137-146. Recuperado a partir de https://revistascientificas.cuc.edu.co/economicascuc/article/view/762

Botero, E. (2016). Análisis del perfil competitivo de la cadena productiva del cacao en el departamento de Arauca. Equidad y Desarrollo, (27), 37-53. https://doi.org/10.19052/ed.3663

Bueno, T. (2004). Diagnóstico de la cadena productiva del cacao-chocolate en el departamento de Arauca. [Cd Room].

Cámara Directa. (2016). Cluster Cacao apuesta de desarrollo para nuestra region. [Online]. Disponible en http:// clustersantander.com/cluster-cacao/

Cardona, M. y López, M. V. (2012). La capacidad organizativa de las redes y las cadenas en la dinámica económica social. Revista Universidad EAFIT, 37(122), 9-21. 
Castellanos, Ó. F., Torres, L. M. y Flórez, D. H. (2010). Agenda prospectiva de investigación y desarrollo tecnológico para la cadena productiva de la panela y su agroindustria en Colombia. Bogotá, D.C.: Giro.

Castellanos, O., Rojas, J., Villarraga, L. y Ustate, E. (2001). Conceptualización y papel de la cadena productiva en un entorno de competitividad. Revista de Ciencias Administrativas y Sociales, (18), 87-98.

Contreras, C. A. (2017). Análisis de la cadena de valor del cacao en Colombia: generación de estrategias tecnológicas en operaciones de cosecha y pos cosecha, organizativas, de capacidad instalada y de mercado. [Doctoral dissertation]. Universidad Nacional de Colombia, Bogotá, D.C., Colombia.

Dalle, D., Fossati, V. y Lavopa, F. (2013). Política industrial:i el eslabón perdido en el debate de las Cadenas Globales de Valor? Revista Argentina de Economía Internacional, (2), 3-16.

Datos Abiertos. (2017). Cifras de Producción departamento de Santander 2017. [Online]. Disponible en https:// www.datos.gov.co/

Espejel, A., Illescas, C., Hernández, A., Santos, A. y Ramírez, A. (2018). Innovación y competitividad en la agroindustria artesanal del queso crema de Chiapas. Económicas CUC, 39(2), 25-38. https://doi.org/10.17981/econcuc.39.2.2018.02

Espinosa-Álzate, J. A. y Ríos-Osorio, L. A. (2016). Caracterización de sistemas agroecológicos para el establecimiento de cacao (Theobroma cacao L.), en comunidades afrodescendientes del Pacífico Colombiano (TumacoNariño, Colombia). Acta Agronómica, 65(3), 211-217.
El Tiempo. (enero 27, 2017). Gobierno y Farc inician programa para sustitución de cultivos ilícitos. [Online]. Disponible en https://www.eltiempo.com/ politica/proceso-de-paz/lanzan-programa-para-sustituir-cultivos-ilicitosen-colombia-37859

Escobar, S. (2017). Planificación tecnológica, competitividad y desarrollo de capacidades locales para posicionar a Colonacionembia como productor de cacaos especiales. Revista virtual PRO, (186), 1-5.

FAO. (2015). Desarrollo de cadenas de valor alimentarias sostenibles: principios rectores. Roma: Organización de las Naciones Unidas para la Alimentación y la Agricultura.

Fedecacao. (2016). Colombia tiene el plan decenal para el cacao. Revista de la Federación de Cacaoteros de Colombia. [Online]. Disponible en http:// www.fedecacao.com.co/portal/images/ recourses/pub_revcolcacaotera/fedecacao-colombia-cacaotera-015.pdf

Fedecacao. (2004). Colombia Mayores Oportunidades para el Cacao. Revista de la Federación de Cacaoteros de Colombia. [Online]. Disponible en https://www.fedecacao.com.co/portal/ images/recourses/pub_revcolcacaotera/fedecacao-colombia-cacaotera-014. pdf

Fernández, V.R.y Trevignani, M. F. (2015). Cadenas Globales de Valor y Desarrollo: Perspectivas Críticas desde el Sur Global. Dados-Revista de Ciências Sociais, 58(2), 499-536. http://dx.doi. org/10.1590/00115258201551

Hernández, J., Chumaceiro, A., Ziritt, G. y Acurero, M. (2018). Cultura para la paz en Colombia. Una aproximación desde las políticas públicas. Opción, 34(86), 612-641. Disponible en http:// hdl.handle.net/11323/2000 
Holmlund, M. \& Fulton, M. E. (1999). Networking for success: Strategic alliances in the new agriculture. (Discussion Paper No. 31769). Saskatoon: University of Saskatchewan, Centre for the Study of Co-operatives. https://doi.org/10.22004/ ag.econ.31769

López, N. y Pineda, K. A. (2013). La exportación de commodities: una estrategia para el desarrollo económico colombiano. Bogotá. D.C.: Universidad Militar Nueva Granada.

Lozano, A. P., Vega, V. y Varilla L. (2017). Desarrollo regional sostenible en zonas rurales: Una aproximación al cultivo de cacao en el departamento de Santander. [Trabajo de Grado]. Universidad Católica de Colombia, Bogotá, Colombia.

Mojica, A. y Paredes, J. (2016). Características del cultivo de cacao en Santander. Ensayos sobre Economía Regional. Bucaramanga: Banco de la República.

Montoya, A., Montoya, I. y Castellanos, O. (2010). Situación de la competitividad de las Pyme en Colombia: elementos actuales y retos. Agronomía colombiana, 28(1), 107-117.

Oliveros, D. (2013). Medición de la competitividad de los productores de cacao en una región de Santander-Colombia. Revista Lebret, (5), 243-267.

ONUDI. (2004). Diagnóstico de la Cadena de Valor Industrial. Una Herramienta Integrada. Viena: ONUDI.

Pabón, M. G., Herrera-Roa, L. I. y Sepúlveda, W. S. (2016). Caracterización socioeconómica y productiva del cultivo de cacao en el departamento de Santander (Colombia). Revista Mexicana de Agro negocios, 38, 283-294.

Perdomo, M. A. (2012). Caracterización de la cadena de abastecimiento y la cadena de valor del cacao en Colombia. [Bachelor's thesis]. Pontificia Universidad Javeriana, Bogotá, D.C., Colombia.
Pérez, M. E., Hernández, J., Acosta, I. y Chumaceiro, A. (2009). Consideraciones teóricas para el análisis de las Pequeñas y Medianas Empresas como fuente de generación de empleo y su correspondencia ética con la Sociedad. Revista Formación Gerencial, 8(2), 272-297.

Pietrobelli, C. \& Staritz, C. (2013). Challenges for global value chain interventions in Latin America. [Technical Note No. IDB-TN-548]. Washington D. C.: Inter-American Development Bank.

Porter, M. E. (1990). ¿Dónde radica la ventaja competitiva de las naciones? Harvard Deusto business review, (44), $3-26$.

Ramírez, J. y González, G. (2016). Dinámica de la cadena priorizada del sector metalmecánico del departamento de Santander en el período 2010-2015. Lebret, (8), 175-199.

República de Colombia. Ministerio de Agricultura y Desarrollo Rural de Colombia. (2016). Informe de Gestión 2016. Bogotá. D.C.: MADR.

República de Colombia. Congreso de la República. (26 de junio de 2003). Artículo 2 [Ley 811]. Diario Oficial No. 45.236.

República de Colombia. DNP, (2014). Propuesta para Desarrollar un Modelo eficiente de Comercialización y Distribución de Producto. Bogotá D.C.: CRECE.

República de Colombia. Minagricultura. (2014). Plan Nacional de Desarrollo de Colombia (2014-2018). Bogotá, D.C.: Minagricultura.

República de Colombia. Ministerio de Agricultura y Desarrollo Rural. (20 de noviembre de 2009). Por la cual se reconoce la Organización de Cadena del Cacao y su Agroindustria. [Resolución 000329/09]. Diario Oficial 47.539. 
República de Colombia. Superintendendencia de Comercio Industria y Turismo. (2012). Cadena Productiva del Cacao: Diagnóstico de Libre Competencia. [Online]. Disponible en https://www. sic.gov.co/recursos_user/documentos/ promocion_competencia/Estudios_ Economicos/Cacao.pdf

Sierra, D. C. (2016). El cacao como producto líder en la sustitución de cultivos ilícitos en el proceso de posconflicto. [Bachelor's thesis]. Universidad Militar Nueva Granada, Bogotá, D.C., Colombia.

Torres-De la Cruz, M., Ortiz-García, C. F., Bautista-Muñoz, C., Ramírez-Pool, J. A., Ávalos-Contreras, N., Cappello-García, S. y De la Cruz-Pérez, A. (2015). Diversidad de Trichoderma en el agroecosistema cacao del estado de Tabasco, México. Revista mexicana de biodiversidad, 86(4), 947-961.

UNODC. (junio 27, 2016). "Cacao para la paz", una iniciativa conjunta. [Online]. Disponible en https://www.unodc.org/ colombia/es/press/2016/junio/cacao-para-la-paz--una-iniciativa-conjunta.html

Oliveros, D. (2013). Medición de la competitividad de los productores de cacao en una región de Santander-Colombia. Revista Lebret, (5), 243-267.

\section{Biodata}

Julio Ramírez Montañez es Magister en Relaciones Internacionales. Flinders University of South (Australia). Profesor de la Facultad de Administración de Negocios Internacionales. La Universidad Pontificia Bolivariana, (Bucaramanga, Colombia). Director del Grupo de Investigación de la Facultad de Administración de Negocios Internacionales (GRICANI). https://orcid.org/0000-0003-0116-3330

Gladys Mireya Valero Córdoba es $\mathrm{PhD}$ (c). de la Universidad Pontificia Bolivariana (Colombia). Decana Escuela de Economía, Administración y Negocios. Universidad Pontificia Bolivariana (Colombia). https://orcid.org/0000-00019733-5306

Paola Martínez Higuera es estudiante de Administración de Negocios Internacionales de la Universidad Pontificia Bolivariana (Colombia). Integrante del Semillero SIGI 